\title{
A Study on Financial-Accounting Methods for Prospecting the Lifetime Value of Hypermarket Business: A Critical Used of Geospatial Method
}

\author{
*Abdul Manaf Bohari ${ }^{1}$, Ruslan Rainis², Malliga Marimuthu ${ }^{2}$ \\ ${ }^{1}$ UUM College of Business, Universiti Utara Malaysia, Malaysia \\ ${ }^{2}$ School of Humanities, Universiti Sains Malaysia, Malaysia \\ *manafdr@uum.edu.my
}

\begin{abstract}
Recently, the hypermarket profitability is an important issue for the world wide retailing industry with vast literature was found on its definitions, measurements, and models of studied. In general, majority of related work showed that various methodologies and models have been applied to evaluate the profitability of hypermarket, where more dominants on financial and accounting methods. Specifically, estimate the hypermarket profitability are always dominating by financial and accounting methods and approaches with finale attention on maximizing the customer lifetime value (CLV). In fact, most of traditional measurement have been used are interest rate, chuck rate, lease, as well as income and consumptions of consumers. However, a little attention has been given to using others variables, as well as spatial based measurement although it has big potential to contributes on prospecting the profitability of hypermarket. In addition, continuously, financial or accounting variables has been improved and reused in different ways where the method itself in overall is still remains as before. The objective of this paper is to overview the weakness of financial and accounting methods with focused on theoretical and applications issues of estimating hypermarket profitability. Secondly, this paper is aimed to suggest geospatial method as alternative ways for bridged the gap of existing works regarding the estimations of hypermarket lifetime value. By using geospatial variables as well as spatial method, this work will contributes on establish new ways of estimated the CLV of the hypermarket where spatial platform is function to visualized the real situations of financial and accounting information as well as it emerge in the real marketplaces. In future, the use of geospatial method will be brings new hope on better understanding on CLV especially how CLV can estimated by both financial-accounting and spatial variables.
\end{abstract}

Keywords: Financial-Accounting Methods; Profitability; Lifetime Value Hypermarket; Geospatial

\section{Introduction}

Over the past decade, the field of customer value management has rapidly emerged as an important area of research in marketing. Beginning with work that started to consider the customer as an important asset of the firm, researchers touch on different views, with Blattberg and Deighton (1996) highlight the management of customer using Customer Equity (CE); Reinartz and Kumar (2000) investigated profitability of long-life customers in a non-contractual setting; and Srivastava, Shervani, and Fahey (1998) developing framework for market-based assets and shareholder value. These early initiatives are important work for extended research, 
specifically on customer value management field. With the rise of important on managing customers as high priority assets, research about customer valuation has grown significantly. In fact, they are focus on using previous customer's information rather than acquiring new information of new customers. This is supported by Lenskold (2003) that shows the value of retaining customers can be as much as 100 percent more profitable than acquiring new customers. Beside this, the financial and accounting methods are widely used for many works of prospecting the customer lifetime value (CLV) where it measures the profitability of hypermarket business. In context of customer relationship management (CRM), CLV is one of it four components, along with key account management, customer portfolio analysis and the relationship lifecycle. Customer valuation has been discussed by several papers in the customer relationship management literature, such as Dwyer (1997); Berger and Nasr (1998) and Malthouse and Blattberg (2005). So far, we see that the value of a customer has long been defined with regard to the longevity of historical financial value where financial instrument are core items of projecting CLV, as far customers engage with the business. However, researchers have criticized this argument, for certain reasons. A works by Reinartz and Kumar (2000) had criticized this method, since they demonstrated that a long life-cycle and the profitability of a customer were not necessarily related. With regard to the works as above, most of these works are focused on using the financial or accounting method, with just doing a little extending the previous version of CLV, and then, reused for projecting the results. Obviously, they are never considers truly new variables, especially spatial variables where it also has potential to in-enhance the capabilities of projecting retailers profitable customers.

The objective of this paper is to overview the weakness of financial and accounting method based on theoretical and applications issues of estimating hypermarket profitability. For that, specific examples regarding the methods and approaches of financial and accounting will be review where it has been used by hypermarket purposely for prospecting their profitable customer. Secondly, this paper is aimed to suggest geospatial method is highlight as alternative ways for bridged the gap of existing works regarding the estimations of hypermarket lifetime value. In fact, the existing of constrains and limitations of financial and accounting method, that is derived new potential of geospatial approach in backing some aspects in estimates $\mathrm{CLV}$ as well as it will be strengthening the current practices prospecting the lifetime value of hypermarket business. In addition, by using geospatial variables as well as spatial method, this work will contributes on establish new ways of estimated the CLV of the hypermarket where spatial platform is practical to presents the real situations of financial and accounting information as well as it emerge in the real marketplaces. In future, the use of geospatial method will be brings new future on better understanding on CLV especially how CLV can estimated by both financial-accounting and spatial variables.

\section{A Critique on Accounting-Financial Methods}

In theory, marketers are dependent on customer engagement for increase the CLV of their customers in any location or places. In contrast, many marketers are willing to lose money on the initial sale knowing they will earn profit on subsequent purchases. But, the path to reengaging customers driven from paid search is far from clear and difficult to analyze because of lacking in CLV valuing tools. The result is marketers cannot assess the information of CLV specifically by using location based customers as references. This will become difficult because real time value of new customer cannot reaches and generate simply form establish 
customer database. Thus, there is no guarantee that these new information on customers will be accounting into currently CLV. In fact, the best way to reengage with all of customers may likely be through additional advancement on CLV prospecting technique especially by introducing geospatial based analysis on the currently practices of original CLV. Basically, customers are important intangible assets of any firms in the business, and for that, it's should be measures in long term projections. Although researchers have emphasized customer relationships and CLV, these concepts have had limited impact on the business and investment community for two main reasons: (a) they require extensive data and complex modeling, and (b) researchers have not shown a strong link between customer and firm value (Gupta \& Lehmann, 2003). Similarly, Rust, Lemon and Zeithaml (2004) emphasized that marketing strategy should focus on projected future financial return using the total value of the customer base. Supporting this idea, Gupta, Lehmann, and Stuart (2004) showed that the earnings of a company, and hence its value, are a function of the total CLV. These issues should be considers the location of customers as main stream for analyzing the customer relationship and CLV because geographical location is contained customers, firms and overall community related to the business. Using geospatial based data are important for assessing these issues because spatial approaches might be able to helps marketers in visualize and modeling the customer relationship and CLV in practical ways, includes clarify the impacts of both concept in location.

Knowing the CLV of individual customers enables a firm to improve its customer selection, customer segmentation, and marketing-resource-allocation efforts as mention by Kumar, Lemon and Parasuraman (2006). With a single view of the customer, Adams (2005) perceived that an organization can take the next step toward building stronger customer relationships, then executing more precise targeting and superior campaigns. Using a variety of analytical tools and processes to deeply analyze customer and prospect data, the company can conduct strategic market segmentation to understand its relative position in the marketplace; strategic customer and prospect segmentation to understand the behavior and value of customers; and tactical customer and prospect segmentation to continually improve marketing campaigns based on initial response With regard to Kumar et al and Adam, CLV can used for analyze every single CLV for each customer, but it is not really enough for in-depth analyses of single CLV. This is because of single value of CLV is not related to geographical customer although believed that single CLV are effecting by many factors, both spatial and non-spatial factors. With concentrate on financial based variables, Doherty (2005) explains that traditionally Return on Investment (ROI) calculations and justifications have involved the hard financial results of an investment. Many definitions exist but in general view, straightforward definition is for a given use of money or resources in an enterprise, the ROI is how much profit or cost saving is realized. These financial based ROI calculations depend totally on hard metrics, usually dollars spent and dollars saved or gained. A number of different techniques can be used to calculate purely financial ROI and some of these ROI calculation techniques include Present Value (PV), Net Present Value (NPV), Return on Investment and Internal Rate of Return (IRR). Again, as mention before, all of it is financial based method is based on monetary and accounting point of view.

Critically, Venkatesan and Kumar (2004) cited that too many marketing managers fail to identify the most valuable customers and are either spending their marketing budget on the wrong customers or in the wrong channels of communication. The measurement of CLV should be able to guide marketing managers make 
three key decisions, as well as (i) which customers should they contact; (ii) what channel should retailers use to contact them; (iii) How much do retailer contact a customer. Typically, customer metrics such as Past Customer Revenue (PCR) and Past Customer Value (PCV) are used to accomplish the task of identifying profitable customers. But these metrics are backward looking and do not provide a future picture of customer profitability. However, it is clear that, both, PCR and PCV measurement never counting spatial based variables as one of measurement although spatial variables have significant contribution toward projecting the profitable customers for future base. Traditionally, income is one of the parameters used in estimating CLV of every single customer where it related accounting-financial methods. CLV based models, as well as the common model discussed by Berger and Nasr (1998); Gupta, Lehmann and Stuart (2004); Venkatesan and Kumar (2004) and Glady, Baesens and Croux (2009) and many more, the demand for used income as major instrument for predicting retailer future prospects continuously rise up and that for, CLV approaches were applied and modified by these researchers with hope to get more accurate and sharply results. Empirically, Nunes and Johnson (2004) noted that a dramatic shift in income level has emerged over the last three decades, heralding the rise of a huge and affluent new consumer group that has gone largely ignored by marketers. In 1970, one out of every 27 households earned a six-figure income. Now that ratio is closer to one out of seven. As important as this growth in income is the growth in buying power this newly affluent group is assuming. The problem for marketers is that these consumers have been spending relatively less and a new approach for wooing and winning the moneyed masses should be introduce to the retailers. In addition, a study by Carminati and Trouvé (2004) found that information about customer profitability still not on the major priority for certain retailers, although at the same time they really need more insight information about customer behaviors, geographic and demographics. Thus, based on the problems stated by Nunes and Johnson (2004) and Carminati and Trouvé (2004), CLV research must consideration on the latest approach, includes geospatial approach.

Plainly, Graf and Maas (2008) explain that the value concept is one of marketing theory's basic elements where as identifying and creating customer value is regarded as an essential prerequisite for future company success. Nevertheless, not until quite recently has CLV received much research attention. Thus, ideas on how to conceptualize and link the concept to other constructs vary widely. Theoretically, Reichheld and Teal (2001) mention that earning the business of a new customer is six to seven times more expensive than retaining an existing one. Under this fact, developing customer loyalty program is important to retain and maintain customer loyalty toward product that offered to market. It makes sense to focus marketing efforts, not only on new customer acquisition, but also on increasing the lifetime value of existing customers. There is enormous potential for improving a company's performance by increasing customer, investor, and employee loyalty. Clearly, loyalty drives profits in direct and quantifiable ways through its impact on growth, learning, and productivity. Loyalty also generates a spiritual energy that powers the value creation process that is at the heart of sustained business success. In many industries, loyalty explains the differences in profitability among competitors more effectively than scale, market share, unit costs, or most other factors usually associated with competitive advantage. However, critically, the concept of customer loyalty is lacking in used of understanding the CLV because it is never confirms anything about return on financial performance, too subjective in measuring the firm profitability, and cannot simply converted to financial value. Thus, for operating and analyzing the CLV in the real market, geospatial method has unique capabilities for better understanding the 
CLV as supported by little studied by ESRI (2007) and Pick (2008). The CLV valuation methods, as well as the traditional financial approaches, such as Return on Investment (ROI), Return on Equity (ROE), price-earnings ratio, and many more are fail to modeling and linkages sharply, between relationship and CLV of customers, with the real location of customers. These measures according to Venkatesan and Kumar (2004) are like CLV provide a forward-looking picture, but less is known about the factors that affect CLV and about the cost of maximizing CLV. Thus, evaluation of the usefulness of CLV and present it as a metric to understand customers and optimize the return on marketing investments have done by using rich customer transaction data from a large multinational firm As opposite of Venkatesan and Kumar, geospatial approaches have capabilities in-modeling and visualizing overall the situation and activities related to customers value in the marketplace, such as customer relationship, customer interaction, customer behaviors, investment community, and many more. Thus, the important point is spatial based approaches is the alternative in prospecting the precise locations of customer and mapping the CLV in the real environment of business. In addition, customer transaction data from large multinational firm, as well as used by Venkatesan and Kumar actually not considers real time based data from spatial and it's not covering several parts of customers.

To date, from the vast literature review, research work on CLV already exist since 1930s and most of them are base their customer evaluation solely on the analysis of historical data from one customer, such as what items were bought in the past and at what frequency. For instance, the new technology developed by IBM allows retailers to estimate the potential lifetime value of relatively new customers and this technology works from two mechanisms which are identified as (i) the spending patterns of a single customer and (ii) the online activity of other more established customers. In further, by monitoring the buying behavior during the initial visits of a new customer, the model are able to assign and classified the customer to a group and then predict spending patterns based on those with the same buying profile. In contrast, this model have no ability for assign and classifying customer values specifically into location based and in results, customers value information placement are still not accurate. So, it is important to classified customer into geographical location because different location of customers have different factors that are affecting customer CLV. With some constrain in the method of financial and accounting and capability of geospatial approach, thus, developing new model that integrating spatial and non-spatial data is vital important to enhanced the performances of prospecting CLV of each customer where current factors related customer will accounting on it. Therefore, some limitation, suggestion and conclusion with stress on geospatial method will highlight to shows the future prospects of the most advanced method and approach that lead the ways on CLV valuation. Ultimately, geospatial is one of the new approaches for enabling the retailer to prospecting more insight and accurate of profitability, compared to financial and accounting or any related model that lies on statistical and mathematical previously used by others researchers. As summary, the monetary value of CLV generated from different components or sources where it was formulated as accounting or financial method. One of the most important components is customer loyalty where these data acquired form customer database of the hypermarket. On the one hand, higher commitment to a company often leads to enhanced purchasing frequency, larger shopping baskets, lower customer price sensitivity, and a stronger resistance to counter offers from competitors. Loyal customers search less for competing product and service offers. However, on the other hand, non-monetary benefits also accrue and may contribute to CLV value. One of CLV disadvantages is it not really counting non-financial instruments in the formulas. Most of researchers are still investigates 
the best ways for in cooperating it into CLV calculations.

\section{Methodology}

Firstly, an interview approach will be used as main method for gathering some information about Accounting-Financial method of prospecting the CLV. The interview is conducting in un-structured format where it was involved academician expert from Universiti Utara Malaysia (4 persons), Universiti Teknologi MARA Malaysia (2 person), LimKokWing University (1), and Universiti Sains Malaysia (1 person) where all of the university was situated in Malaysia. Secondly, key-person of hypermarket has selected as respondents which are focused on International Hypermarkets in Seberang Perai of Penang in Malaysia. There are 20 key-people of hypermarkets; as such marketing researchers (4 persons), Finance/Accounting managers (4 persons), Sales managers (4 persons), Acquisition Manager (4 persons) and supervisor's (4 persons) are volunteers to cooperate to this study. Totally, there are 28 respondents' that volunteer to be interviewed in this study.

\section{Results}

Theoretically, CLV value projected based on customer information such as from historical buying record, customer database, customer loyal card, and many more. All factors related to CLV as well as financial base are fully depend on that information running base on certain model and software of CLV. Moreover, projecting value of CLV can be estimate for five years series. These opinions are agreed by 19 of 20 respondents. In contrast, an expected CLV result actually never refers to geospatial or geographical views although spatial based factors have highly significant or contribution to improvise the results of expected CLV, as shared by 19 of 20 respondents. For instance, cultural and local environment of customer, such as drive time, customer experiences, and relationship between customers, are the factors that significant impact toward expected CLV. Thus, any results of CLV that produced from established CLV models are highly differs from the real one where it potential to create gap between projected and real value of CLV. In practice, the gap is widening between the CLV expected and the CLV in the real environment (spatial based value) because of the variations in customer information and customer experience in specific location of geographical environment, where 7 of 8 academician and 18 of 20 hypermarket key-persons are shared the same idea. Some of research findings indicate that a gap exist between consumers' rising expectations value and what they actually experience in the real environment of geographical matter. In addition, it is so difficult to manage the current change of customers in the marketplace without using spatial based platform for analyzes it. In traditional method, companies are differentiating their customer based on service, either their satisfied or not satisfied with the services or not. Some of customer may consider themselves as "very satisfied" but rate their experiences as "excellent". In practical, the business continuously assumes that the customers are maintaining their satisfactions rates, although by time they lose their customers in futures. So, this is the real problem related to estimating the CLV without using spatial based analyses, and still happened in the world of consumers.

Expected CLV originally derive from any customers that make transaction to the business. But, expected CLV never consider non buyer as their customer although non buyer probably will be their potential contributors 
in future, as mention by where 6 of 8 academician and 17 of 20 hypermarket key-persons. The important question have arise is how to assessing the non buyer customer but still have value to the firms. How to get the information on non buyer customer who is never made any transaction to the business. Sometimes a valuable customer may be the person who never buys a thing from them, but they must consider as a part of CLV expected value. The firm must know how to visualize and assess the profitability of non buyer who nevertheless influences the bottom line of business. However, sadly the established CLV models cannot support this function because of lacking in mapping the non buyer information, where all of 8 academician and 19 of 20 hypermarket key-persons are shared the same agree on these ideas. In term of classifying profitable and unprofitable customers, how well do the retailers know insight their customers? Usually, the hypermarket has utilized their customer database where probably know them by name, address, income, educational background, and any other personnel details. These answer are shared the same opinion by where 7 of 8 academician and all of hypermarket key-persons are shared the same idea. However, in today's highly competitive market, conducting the customers as usual will not help the business to succeed and performance well in future. Thus, the business must go deeper, as far as they can. For instance, by provide the right services to your customer, at the right time, to the right location of customers, this will enabling you to be more effective in prospecting the most profitable and unprofitable customers. In addition, where 5 of 8 academicians mention that geospatial approaches are one of techniques that can be used for in-depth analyzing the insight of customers, especially in differentiates un-profit and profitable customers. Fundamentally, CLV valuation approaches are dominating by financial approaches with highly consideration on financial instruments. The CLV valuation actually derives from organizational perspectives and takes to account every single measurement related to profitability. Seriously, most of the instrument is based on tangible asset that what they can control internally and projecting value of CLV actually based on data what they have. This kind of valuation approaches is have limited capabilities because it's not considers external variable surrounding the store and market, as mention by 25 of 28 respondents. In practically, this is not really geospatial valuation and have impact on future values of customers that what they predicted. What actually happen in geographical area of business always missed from their profitability view and never take into accounting in their valuation although the chance of geographical event and variables as agreed by 26 of 28 respondents. This is serious case because previously CLV valuation never integrates spatial information as parts of their measurement. So far, they are no study done using geospatial based instrument in calculating customer CLV and in the end of results, it's never relates CLV to any types of geographical variables.

A critical success factor for retailing business today is its ability to use information sources and contained knowledge in the most effective way. This strategic use of data can result from opportunities presented by discovering hidden, previously undetected, and frequently extremely valuable facts about consumers, retailers and suppliers, business trends, and direction and significant factors. The information as above is coined out by 24 of 28 respondents. Knowing this information, an organization can formulate effective business, marketing, and sales strategies; precisely target promotional activity; discover and penetrate new markets; and successfully compete in the marketplace from a position of informed strength. But, in the reality, all of this information is distributed in the spatial environment where accounting-financial method has not consider and counting into it projection. As example, when performing ROI analyses, organizations have begun to take non financial benefits into account. These non financial benefits include improved services to 
the customer, reduced wait times, increased public safety, decreased operational errors and assuring public health. In some cases, models or assumptions are used to translate these non financial benefits into financial metrics so that traditional ROI calculations can still be used. The models can be very complex and, as with any analysis which uses key assumptions, is based on the validity of those assumptions. Therefore, geospatial methods by using GIS software are the only technology that can use for collecting, storing, manipulating, and analyzing the data. Up to date, geospatial emerged as an important factor in the business world over the past ten years. In addition, the GIS trends are towards smaller devices, coupling of GIS with associated technologies, web platforms, and enterprise wide applications. Finally, GIS and geospatial technologies can be strategic and advance firms, especially in estimating the most profitable customers to hypermarket business.

Geospatial Method as Prospector for the CLV: Basically, customers are not equally value and never produce same value to retailers and it's depending on some factors, including environment and local factors of market. Suppose retailer profitable is not presenting the amount of profit, but more important is it should presenting CLV within geographical perspectives because of retailers need this kind of information in-enhance their future prospect customers. Using mathematical or statistical analysis and presentation is not enough for investigates the difference value within various types of customers. Due to these issues, geospatial or Geographical Information System (GIS) plays important rules in term of assimilates and differentiates the location of profitable customers. Epstein, et al., (2008) noted that some customers are more profitable than others. Conversely, some are downright unprofitable. Despite enormous variations in profitability, many companies continue unprofitable relationships with customers, often providing them with pricing and service levels identical to those received by the most profitable ones. Why? In most cases, companies simply do not know who the unprofitable customers are. As such, they cannot develop marketing strategies or manage costs accordingly. It's important to analyze the customer value, purposely for determine which location of customer are more profitable and valuable to retailers. Glady, et al. (2009) identified that valuing customers is a central issue for any commercial activity and the establish method as well as CLV is used to projected the discounted value of the future profits that this customer yields to the company. In order to compute the CLV, one needs to predict the future number of transactions a customer will make and the profit of these transactions. With the Pareto/NBD model, the future number of transactions of a customer can be predicted, and the CLV is then computed as a discounted product between this number and the expected profit per transaction. Usually, the number of transactions and the future profits per transaction are estimated separately. However, the Pareto/NBD model as introduced by Glady et al.,(2009) is not ever consider any kind of spatial instruments and the projected values comes from this model actually still lack of accuracy, especially in term of geographical manners. Suppose future profits should directly relate to spatial based information because everything changes in geospatial based will affecting the future value projected from CLV. Thus, projected values of CLV either utilized the original version of CLV or Pareto/NBD model is never meet the reality of geospatial view because it never includes the real time based measurement.

As example, in the enterprise business systems, which up to now have had minor spatial aspects, spatial data are become more critical issues. In the ERP for one large business, for examples, data shows that over 98 percent of analysis is non-spatial and only 2 percent is spatial. Hence, proportion of the non-spatial uses must be considered in recognizing the perceived importance of spatial data and the priorities given by managers 
and other stakeholders in utilizing it (Pick, 2008). In contrast, researcher as Zhao (2000) noted that more than 80 per cent of all information in an organization can be geographically referenced. While, GITA (2005) coated that information has a spatial reference if it can be tied to a map. Comparing the fact rise by Pick (2008) with Zhao (2000) and GITA (2005), actually these will effecting the projected value of customers because projected CLV is based on data in organization, while conversely spatial CLV is derive from spatial based. Thus, highly different of data sources in organization, will derive highly potential to create the big gaps between expected CLV and spatial CLV. In this case, domination of non-spatial data finally will contribute to un-balances results because of the results of CLV are tendencies skewed toward non-spatial bases. Surely, this is one of reasons why the significant different occurs between projected CLV and spatial CLV. Theoretically, Toppen and Wapenaar (1994) point out that retail marketing is one of the most promising fields of geospatial application. In general, retail marketing is a question of demand (consumers) and supply (shops or shopping centers). Both aspects are easy to pinpoint to a geographic location and are therefore, it is interesting for performances any kind of spatial based data analysis using geospatial or GIS tools. In the early phase of emerging GIS in business field, the use of geospatial in retail marketing, mostly, was limited to mapping the results of marketing research. Nowadays, because of hardly change in GIS technology, the mapping activity are become as basic requirement for retail marketing, and consequently, more and more analytical operations are performed within a GIS environment. Some examples are the delimitation of catchment areas, the identification of retail sites, and competitor analysis. Actually, for most of these operations, new tools had to be implemented within existing geospatial software and moreover, requirement for more powerful tools arises in retail marketing segments.

In the recent years, the application of geospatial in business has grown rapidly. Major retailers, automobile dealerships, video rental companies, media organizations, and fast food corporations are just some of the many businesses around the world that have discovered the value of geospatial. Thus, business strategists are finding geospatial to be an ideal tool for identifying and expanding markets, and increasing profits (Zhao, 2000). Moreover, in high platform business operation, geospatial are become more sophisticated to invest especially to small and medium sized business, because of its initial costs can be highly compared to estimates ones. Also, the tangible benefits of it capabilities can take several years to materialize in the real situations. In the one hand, the emerging of geospatial software in the marketplaces actually create more competitions among software vendors, and will motivate them to make better improvement in tools and application related to geospatial software. In the other hand, retailing will get the benefits in capturing and mapping their customer values, market segmentation, and any changes in the marketplaces. In the end, the retailers are be able to maximize the geospatial tools in prospecting their potential customers that will contributes highly value to their profitable or annual performances. This is related to ESRI (2007) that noted geospatial software notes as important software that can be apply to performance business based analysis, such as site and location, business continuity plan, facilities and equipments, retail trade area, and so on. Practically, geospatial plays important roles as keys for retailing firms for establishing customer database by utilizing the spatial environment as platform. Normally, in previous practice of retailing, analysis of customer by marketers or executives is done utilizing Marketing Information Systems, Customer Relationship Management software (CRM), Marketing Decision Support System, Sales Force Automation (SFA) Systems, Customer Data Mining Technique, and many more. But, extremely, geospatial offers the practical tools and solution which is allows 
the marketers to performing their analysis under the spatial platforms. Actually, this is special capabilities provided by geospatial and never experiences by others kind of customer software management. For instances, prospecting the retailer profitability by utilizing non-GIS software, it just presenting the results in graph, table or chart view. But, GIS software wills performance more than that, which is supply geographical platform for more clear views in analyzing the most profitability customer for retailers. Furthermore, geospatial allows the marketers to relate and understanding all the factors that related to retailers profitable within the geographical locations. There is important facts because of most information is geographically spread and referred, just as mention by Zhao (2000) and GITA (2005).

It is crucial for a company to identify which are its most valuable and least profitable customers so that appropriate customer-specific marketing strategies can be developed and fixed to the place. Recklies (2006) coined researcher develops a comprehensive CLV measure model with combines the up-selling, cross-selling, network influence opportunity, and also considers the churn risk. By regarding the market as a social network, the social influence role of a customer is explicitly modeled into the CLV evaluation. The result from the CLV model is used as a metric for customer selection and this model empirically, validated by the application to a company in the health care industry. However, although Recklies were developing comprehensive CLV for estimate the profitable customer, but it is still not enough capability in assimilates the different value of CLV in the real location. The Model that introduced by Recklies is still not considering spatial measurement and of course, the presentation of CLV is cannot implemented in geographical perspectives which are referring to specific location in the real world. Fundamentally, all people may be created equal, but the same can't be said for customers. Everyone knows that some customers are more profitable than others. Conversely, some are downright unprofitable. Despite enormous variations in profitability, many companies continue unprofitable relationships with customers, often providing them with pricing and service levels identical to those received by the most profitable ones. In most cases, companies simply do not know who the unprofitable customers are. As such, they cannot develop marketing strategies or manage costs accordingly unless their get accurate results on it. Companies don't necessarily need a state-of-the-art database or analytics technology to improve customer profitability. Because of their unique qualifications and abilities, financial managers should take the lead in translating analysis to action and creating the culture of value (Epstein, et. al., 2008). Here, the un-ability of traditional based CLV do makes the differentiation of customers profitability value actually one of the constrain they have. To ensure this question well solved, geospatial variables should considered in redesign and redevelop the new version of CLV for apply in differentiates the high and lower value of each CLV of customers.

Gupta, Lehmann and Stuart (2004) believed it is increasingly apparent that the financial value of a firm depends on off-balance-sheet intangible assets. Here, the most critical aspect of a firm is refers to its customers. Specifically, valuing CV is vital important to makes it feasible to value firms, including high-growth firms with negative earnings. Besides that, value of a customer are defines as the expected sum of discounted future earnings. By using publicly available data for five firms, they find that a $1 \%$ improvement in retention, margin, or acquisition cost improves firm value by $5 \%, 1 \%$, and $0.1 \%$, respectively. They also find that a $1 \%$ improvement in retention has almost five times greater impact on firm value than a $1 \%$ change in discount rate or cost of capital. The results show that the linking of marketing concepts to shareholder value is both 
possible and insightful. However, financial based instruments, as well as mention by Gupta, et al. (2004) is not really used for understand what is going on in the real market. This is because of the financial instruments always not display in geospatial views, unless they used geospatial based analysis. The calculation of CLV is straightforward, calculating as a net present value of the future cash flows of a profitable customer. CLV allows for product differentiation according to expected customer value in three different customer classification, as well as high, medium, and low-value customers. In that way, the Retailers expected to gain substantial insight into marketing decision-making and they are able to determine an equitable of every single store performance. However, it really not successful works because CLV cannot visualize the spatial based problems. This is support by Pauler, Trivedi, and Gauri (2009) that indicates one of the major problems faced by the management at supermarket chains is the determination of a fair and equitable assessment of individual store performance keeping in mind the variation in store features, competitive environment, and socio-demographic characteristics of the consumers facing each location. Specifically, in a densely populated highly developed urban environment, such trading areas have very high overlaps (90 - 95\%) between stores, rendering the use of finite border models not only ineffective, but incorrect to use. So that, because of limitation of CLV in detecting spatial based issues, as arise by Pauler et al. (2009), it is important to explore another variables where as closely to spatial environment, such as demographics, religions, lifestyles, drive time, and many more.

In most recent CLV research conducted, as mention before, they are successful to predicting CLV value and identified which customer are high in CLV and ones are low in CLV by using CLV calculators such as Model MAX introduce by ASA; The HBS Toolkit Lifetime Customer Value Calculator (Harvard Business School); and Customer Lifetime Value Calculators (VOX). However, an even more challenging issues with concerns how to turn unprofitable customers into profitable ones, especially using location as baseline. Actually, this would require knowledge of why certain customers behave in a more profitable way than others in specific location because different locations of customer almost have different level of CLV. In other words, what do profitable customers actually do which distinguish them from less profitable customers? Although customers have same level of monthly incomes, housing and demographic background, but it still difficult in analyze and differentiate profitable and un-profitable customers, because of differences in environment of market location. While the present study does not provide a rich understanding of this issued, it does suggest that spatial variables as new variable to ensure to be explored in more depth regarding CLV view, especially from the side of non profitable customers. Thus, it is important to explore the potential used of geospatial platform where it has offers more practical used of both financial-accounting and spatial information as discusses before. Until year the year 2010, most of researcher still used monetary or accounting based measurement for estimating CLV, with identified as total value of average customers, potential contribution of customers to the business over a period of time, and total revenue gained from current customer. For examples, Glady, Baesens and Croux (2009) provide a framework for evaluating churner classification techniques based on a financial measure of accuracy, which is the profit loss incurred by a misclassification, considered from a customer lifetime value perspective. In conjunction of CLV, geospatial approach utilize for defining new ways of prospecting the CLV of each customer of hypermarket. The fact is geospatial method has potential to apply in various kinds of research and area as well as the data is geographical referenced.

\section{Conclusion}


Despite above mentioned disadvantages of CLV, there is few companies succeed to accurately calculate it due to shortcomings and limitations. At the same time, geospatial parameters looks as new potential measurement for enhancing the capabilities of prospecting CLV values, both for individual and group of customers. Primarily, from literature review works as above, CLV technique has requires the firm to grasp the long-term potential value of the customer, which insinuates projecting effectively the financial instruments, as well as revenues and costs into the future. However, the financial-accounting techniques that used for the forecasting and modeling of future customer profitability in terms of spending rate and frequency, in practical still subject to statistical error and need to do some adjustment of it. Moreover, useful CLV analysis requires both spatial data and readymade data as such customer database, historical purchasing data, online database, and so on. Hence, geospatial becomes inappropriate for new firms and new products where historical data do not exist and variations in customer behavior cannot be identified. Understanding market areas, trade area, and customers is critical to the success of any business and they always utilize projected CLV to estimate their future profitability. In reality, the business will face the huge competing with others business especially in prospering their customer market share. By using traditional model of financial-accounting to prospecting the CLV result, the businesses are unable to identify if their trade areas overlap each other's or cannibalize each other. This is because of traditional methods of CLV are unable to running under the spatial surface of geographical marketplaces and practically, the real result of CLV cannot generated as it in the real once. In the retailing industry on Malaysia, for example, one of the criteria in establishing hypermarket is to guarantee that there is no overlap in each hypermarket customer territory. It is because of that will creates another problem in future and the potential for cannibalization of any hypermarkets in nearest area. In addition, traditional CLV methods never have any ability to identify spatially all the retail trade area, customer segmentation, product distribution, and many more. Finally, the retailers need enhance original version of CLV

method by considering geospatial as main platform for produce more precise CLV in future business prospects.

\section{References}

Adams, A. L., (2005). Find and keep the customers you want: The customer insight mandate. Chicago: Accenture Inc.,

Berger, P. D. \& Nasr, N. I. (1998). Customer lifetime value: Marketing models and applications. Journal of Interactive Marketing, 12(1), 17 - 30.

Blattberg, R. C. \& Deighton, J. (1996). Manage marketing by the customer equity test. Harvard Business Review, 74, 136-44.

Carminati, A. \& Trouvé, O. (2004). The CIES marketing study leveraging customer insight to achieve high performance. Chicago: Accenture \& CIES.

Doherty, M. (2005). Finding your spatial return on investment in local government. Intergraph Corporation: Mississauga, Ontario.

Environmental System Research Institute (ESRI). (2007). GIS for retail business. GIS Best Practice (February 2007). California: ESRI.

Epstein, M. J., Friedl, M. \& Yuthas, K. (2008). Managing customer profitability: Determine which customers are 
most valuable to your organization. Harvard Business School: December, 2008.

Graf, A. \& Maas, P. (2008). Customer value from a customer perspective: A comprehensive review. Journal of Financial Business, 58, 1-20.

Glady, N., Baesens, B. \& Croux, C. (2009). A modified pareto/NBD approach for predicting customer lifetime value. Expert Systems with Applications, 36, 2062-2071.

Gupta, S., Lehmann, D. R. \& Stuart, J. A. (2004). Valuing customers. Journal of Marketing Research, 41(1), 7-18.

Gupta, S. \& Lehmann, D. R. (2003). Customer as assets. Journal of Interactive Marketing, 17(1), 9 - 24.

Kumar, V., Lemon, K. N. \& Parasuraman, A. (2006). Managing customers for value: An overview and research agenda. Journal of Service Research, 9, 87.

Lenskold, J. (2003). Retention marketing profitability: ROI challenges influencing the retention versus acquisition debate. Marketing Profitability White Paper Series. Manasquan, New Jersey: Lenskold Group Inc.

Malthouse, E. C. \& Blattberg, R. C. (2005). Can we predict customer lifetime value? Journal of Interactive Marketing, 19(1), 2 -16.

Nunes, P. \& Johnson, B. (2004). Mass affluence: Seven new rules of marketing to today's consumer. Boston: Harvard Business School Press.

Pick, J. B. (2008). Geo-Business: GIS in the digital organization. Singapore: John Wiley \& Sons, Inc.,

Pauler, G., Trivedi, M. \& Gauri, D. K. (2009). Assessing store performance models. European Journal of Operational Research, 197, 349 - 359.

Recklies, D. (2006). PEST- Analysis, www.Themanager.org.

Reichheld, F. F. \& Teal, T. A. (2001). Loyalty effect: the hidden force behind growth, profits, and lasting value. Boston: HBS press Book.

Reinartz, W. J. \& Kumar, V. (2000). On the profitability of long-life customers in a non-contractual setting: An empirical investigation and implications for marketing. Journal of Marketing, 64(4), 17 - 35.

Rust, R. T., Lemon, K. N. \& Zeithaml, V. A. (2004). Return on marketing: Using customer equity to focus marketing strategy. Journal of Marketing, 68,109 -127.

SAP, A. G. (2008). Maximizing store profitability with sap for retail: Levers that improve store performance. Retrieved on January 28, 2009, from: http://www.sap.com/retail.

Srivastava, R. K., Shervani, T. A. \& Fahey, L. (1998). Market-based assets and shareholder value: A framework for analysis. Journal of Marketing, 62, 2-18.

Toppen, F. \& Wapenaar, H. (1994). GIS in business: Tools for marketing analysis. The Hague: EGIS Foundation.

Venkatesan, R. \& Kumar V. (2004). A customer lifetime value framework for customer selection and optimal resource allocation strategy. Journal of Marketing, 68, 106-125.

Zhao, L. (2000). Integrating rank correlation techniques with GIS for marketing analysis. Geo Computation 2000 Sydney. School of Geography, the University of New South Wales. 